\title{
Reestruturação produtiva brasileira recente
}

\author{
Rafael Camargo de Pauli
}

Luciano Nakabashi**

RESUMO - Atualmente, há poucas dúvidas de que o Brasil passou por um importante processo de reestruturação produtiva que teve início em meados da década de oitenta. Adicionalmente, a partir da década de noventa, a abertura comercial e os ciclos de sobrevalorização cambial trouxeram à tona a discussão dos efeitos das alterações em variáveis econômicas sobre a estrutura produtiva brasileira. O objetivo do presente estudo é incluir, nesse debate, alguns aspectos relacionados à qualificação dos trabalhadores.

Palavras-chave: Mudança estrutural. Câmbio. Desempenho econômico.

\section{INTRODUÇÃO}

O debate sobre a reestruturação produtiva brasileira está longe de apresentar um consenso. Um dos motivos é que, como afirma Krüger (2008, p. 331), "não há uma teoria geral da mudança estrutural, mas (...) uma variedade de abordagens teóricas que tratam da mobilidade setorial entre os três setores da economia privada e entre os subsetores dentro destes setores".

Um dos modos de se verificar o padrão de reestruturação produtiva em uma determinada economia é através de alterações em seu mercado de trabalho. Os deslocamentos da força de trabalho entre os diversos setores de atividade e as características dos trabalhadores, como escolaridade e nível salarial, têm sido utilizados para identificar padrões da atual reestruturação produtiva brasileira. ${ }^{50}$

Neste sentido o presente artigo tem por objetivo verificar o padrão recente da reestruturação produtiva brasileira através dos deslocamentos da força de trabalho entre os setores da economia, bem como observar as diferenças nas qualificações dos trabalhadores segundo os setores de atividade.

O trabalho irá verificar se o padrão de deslocamento da força de trabalho da economia brasileira a partir de 1990 é condizente com aquele desenvolvido pela teoria econômica e comum em países desenvolvidos. Pretende-se verificar quais setores estão

\footnotetext{
* Mestrando do Programa de Pós Graduação em Desenvolvimento Econômico (PPGDE) da UFPR e supervisor do Boletim Economia \& Tecnologia. Endereço eletrônico: rafaelcdp@gmail.com.

** Doutor em Economia pelo CEDEPLAR/UFMG. Professor do Departamento de Economia da Universidade Federal do Paraná (UFPR). Endereço eletrônico: luciano.nakabashi@ufpr.br.

${ }^{50}$ Ver, por exemplo, Porcile et al (2008) e Scatolin et al (2007)
} 
crescendo mais e se há diferenças substanciais quando analisada a escolaridade. Para isto, será realizada uma releitura preliminar a respeito da teoria da reestruturação produtiva. Em seguida, será realizada a análise empírica e, por fim, as conclusões serão apresentadas.

\section{ABORDAGEM DOS TRÊS SETORES}

Para alguns autores, a indústria é o grande núcleo gerador de ganhos de produtividade através da geração e difusão de tecnologia para o conjunto da economia. Kaldor (1957) argumenta, em seu trabalho clássico, que a indústria é o lócus por excelência do progresso técnico. Furtado (1972), também enfatiza esse ponto no caso da economia brasileira: “... a atividade industrial condiciona o comportamento global da economia e os investimentos industriais são o canal por onde penetra o progresso tecnológico.” (p. 34). Hirschman (1958) já tinha sugerido um argumento similar, apontando que a indústria teria maior potencial para gerar efeitos de arraste (linkages) sobre o conjunto da economia.

Dentro do debate sobre o papel do setor industrial na economia e focando na análise da reestruturação produtiva, a abordagem dos três setores é a mais difundida atualmente. Ela se fundamenta, em primeiro lugar, na hipótese da "hierarquia das necessidades" (SCHETTKAT e YOCARINI. 2003, p. 4). Esta remonta Fisher (1939, apud KRÜGER, 2008), que observou haver uma regularidade no deslocamento da força de trabalho entre os setores: 1) primário, sendo este composto por atividades agrícolas e correlatas; 2) setor secundário, que é composto por atividades manufatureiras; e 3) o setor terciário, composto por atividades de serviços. Esse deslocamento ocorreria do primeiro para o segundo, em uma primeira etapa, e deste para o último, em uma segunda etapa, na medida em que a renda média da população aumentasse.

Neste sentido, Fisher (1952, p. 828) sugeriu que o melhor meio de classificar os setores seria através da determinação das elasticidades renda das demandas dos produtos de uma economia, o que demonstra a relevância que o autor imputava à sua hipótese. Schultz (1945, apud Fisher 1952, p. 828), por exemplo, propôs que se a elasticidade renda de um bem estivesse entre 0 e , 5, 0,5 e 1 ou fosse maior que um, a firma deveria ser classificada no setor primário, secundário e terciário, respectivamente.

Já Rowthorn e Ramaswamy (1999, p.19) afirmam que, "de acordo com Clark $(1957)^{51}$, a desindustrialização em economias avançadas seria uma conseqüência natural do deslocamento da demanda da manufatura para os serviços".

${ }^{51}$ Estes autores atribuem a Clark (1957) a fundamentação da hipótese da hierarquia das necessidades. 
Em segundo lugar, a abordagem dos três setores se baseia na hipótese de diferencial de produtividade entre os setores. Segundo Krüger (2008, p. 338) foi Fourastié $(1949,1969)$ quem primeiro estabeleceu tal hipótese ao argüir que "as diferentes taxas de crescimento da produtividade entre manufaturas e serviços estão associadas com uma grande realocação do trabalho da indústria para o setor de serviçoo".

Contudo, um dos primeiros modelos concernente ao dinamismo industrial, como agente da reestruturação produtiva, a exercer influência apreciável foi o de produtividade desequilibrada, de Baumol (1967). Nele é considerada uma economia com dois setores: um com atividades "tecnologicamente progressivas, nas quais as inovações, a acumulação do capital e as economias de escala contribuem para um aumento cumulativo no produto por horas trabalhadas" (que pode ser considerado como setor industrial); e "outro com atividades que, por suas naturezas, permitem somente 'aumentos esporádicos' na produtividade" (que pode ser considerado o setor serviços). (BAUMOL. 1967, p.415- 416).

Um resultado importante do modelo é o de que "se a razão dos produtos dos dois setores permanece constante", com o passar do tempo, "uma parcela cada vez maior da força de trabalho total deve ser transferida para o setor não progressivo e o montante da força de trabalho no outro setor tenderá a zero.” (BAUMOL. 1967, p.419)

Outro resultado relevante do modelo é descrito em Krüger (2008, p. 338):

no caso de um aumento na participação do setor estagnante, a quantidade de trabalho deslocada em direção à este será ainda maior. No limite, quando $t$ tende ao infinito a parcela do trabalho empregada nos serviços tende a 1 e na manufatura tende a zero. A taxa de crescimento do produto da economia tenderá a zero no limite.

Este resultado é conhecido na literatura como estagnação assintótica.

Seguindo Baumol (1967), Rowthorn e Ramaswamy (1999) sugerem que a evolução da partilha da mão-de-obra na economia depende, principalmente, das tendências dos produtos e produtividades dos setores industrial e de serviços.

As duas hipóteses descritas acima (da hierarquia das necessidades e do diferencial da produtividade) estabelecem que com o aumento da produtividade do setor industrial há uma liberação da força de trabalho de tais atividades, com uma expansão da quantidade de trabalhadores empregada nos serviços. Adicionalmente, estudos empíricos em países desenvolvidos mostram que os trabalhadores menos qualificados são os que mais perdem participação no total de empregos do setor industrial. 


\section{EVOLUÇÃO RECENTE DA ESTRUTURA PRODUTIVA BRASILEIRA}

De modo a analisar a mudança estrutural brasileira recente, o Gráfico 1 descreve a evolução da participação do emprego formal segundo setores do Instituto Brasileiro de Geografia e Estatística (IBGE), que abrange os trabalhadores declarados na Relação Anual de Informações Sociais (RAIS) do Ministério do Trabalho e Emprego (MTE) de 1990 a 2008. Para os anos de 2007 e 2008 foram utilizados os dados da RAIS e do Cadastro Geral de Empregados e Desempregados (CAGED), que é declarado mensalmente pelas empresas que registram admissões ou desligamentos em seu quadro de funcionários. Aos valores da RAIS de 2006 foram acrescidos os saldos mensais de admissões e desligamentos disponíveis no CAGED, o que possibilitou a atualização dos dados até o mês de setembro de 2008.

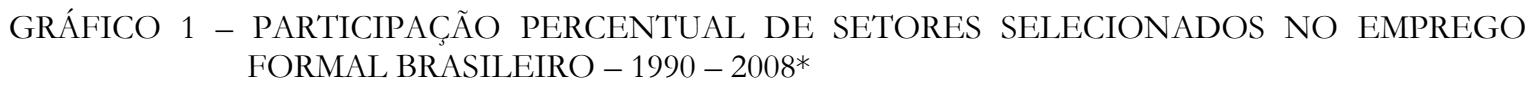
FORMAL BRASILEIRO - 1990 - 2008*

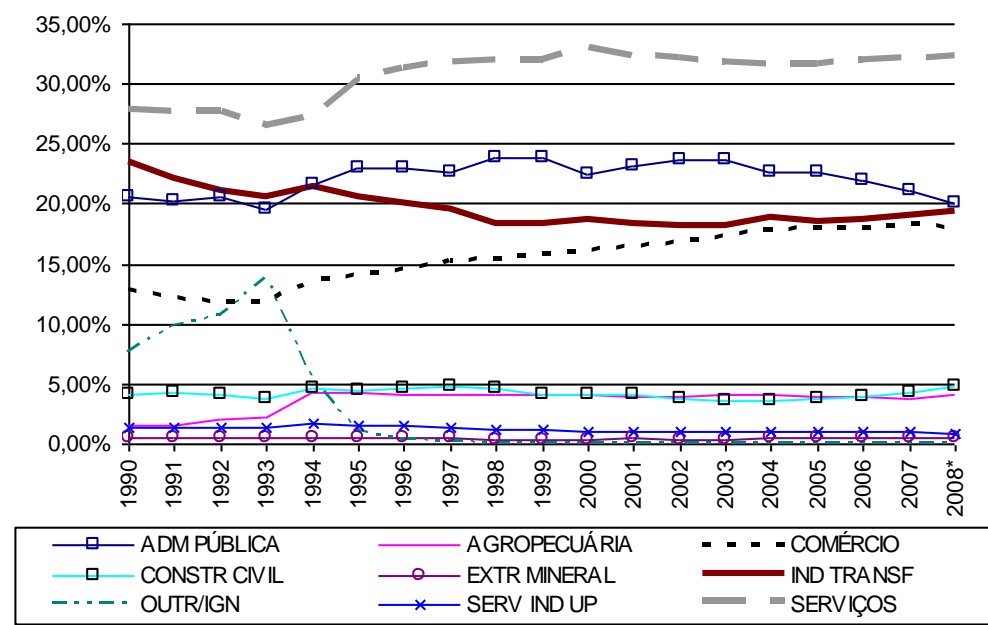

FONTE: Elaboração própria com as bases de dados RAIS e CAGED. Disponível em: https://sgt.caged.gov. br/index.htm. Acesso em: 04/09/2008.

NOTA: $\left(^{*}\right)$ Para o ano de 2008 os valores são referentes até setembro.

É possível perceber um aumento na participação dos Serviços e Comércio, além de uma queda na participação da indústria de transformação, sendo este o setor que mais perdeu participação entre 1990 e setembro de 2008, passando de 23,55\% para 19,33\%, no período. Os setores de comércio e o de serviços passaram de 12,84\% e 27,8\%, em 1990, para 18,01\% e $32,19 \%$, em setembro de 2008, respectivamente ${ }^{52}$. Estes resultados são condizentes com a

52 Pode-se atribuir parte da evolução dos setores Comércio e Serviços, apresentados de forma separada no Gráfico 1, à melhoria do processo de declaração da RAIS por parte das empresas. Observa-se que o setor "Outros e Ignorados" apresentou queda substancial, até chegar a quase zero, em 1996. A partir deste ano, no entanto, aqueles dois setores continuaram apresentando acréscimos no número de trabalhadores e na participação no emprego total, ainda que menos expressivos. Assim, mesmo que a melhora na declaração tenha se dado principalmente nesses dois setores, é inegável que ocorreu um efeito relevante de migração de mão-deobra para os mesmos. 
abordagem dos três setores ${ }^{53}$, uma vez que a década de 1990 registrou ganhos de produtividade no setor industrial ${ }^{54}$.

Observa-se também que, a partir de 1999, o setor da indústria de transformação apresenta mudança na sua tendência, passando a ficar estável até 2005 e ascendente a partir de então. Isto é reflexo, principalmente, do ciclo de queda da taxa Selic iniciado naquele ano e da aceleração da atividade econômica mundial.

Ainda, para saber que tipos de empregos estão sendo gerados em cada setor, realizou-se uma classificação destes de acordo com seus respectivos níveis de escolaridade média, também com os dados da RAIS (Gráfico 2, próxima página).

Observa-se que, em todos os setores, o número de empregos para as classes menos escolarizadas (do "analfabeto" ao "do $6^{\circ}$ ao $9^{\circ}$ ano do fundamental incompleto") caiu entre 1990-2006, com exceção do setor Serviços que apresentou aumento de 14,7\% na faixa "do $6^{\circ}$ ao $9^{\circ}$ ano do fundamental incompleto". Por outro lado, para os empregos com Fundamental completo ou com graus mais elevados de escolarização ("médio incompleto" ao "superior completo") todos os setores registraram elevação no número de empregos. Em relação aos empregos com nível superior completo, destacam-se os setores de serviços e de administração pública, que apresentaram, entre 1990 e 2006, acréscimos de 1,23 milhão e 1,51 milhão, respectivamente (177\% e 164\%, em termos porcentuais). Por outro lado, os setores indústria de transformação e comércio apresentaram acréscimos líquidos de apenas 166.353 e 181.008 (ou 74\% e $216 \%$ ), respectivamente.

Pelas evoluções apresentadas pelo setor Serviços, depreende-se que não existe um único padrão predominante de absorção da força de trabalho. Se o comércio for incluído no setor de serviços, poderemos observar três tendências predominantes: 1) aumento de 98,76\% de empregos com ensino fundamental completo; 2) aumento de 348,4\% de empregos com ensino médio completo e 3) aumento de 180,83\% de empregos com ensino superior completo.

\footnotetext{
${ }^{53}$ Vale lembrar que no desenvolvimento desta teoria, o setor comércio é incluído ao setor de serviços.

${ }^{54}$ Carvalheiro (2003) estima que a produtividade da indústria brasileira cresceu 27,53\% entre o período de 1990 a 2000 , enquanto a produtividade do setor de serviços caiu $2,43 \%$ no mesmo período.
} 


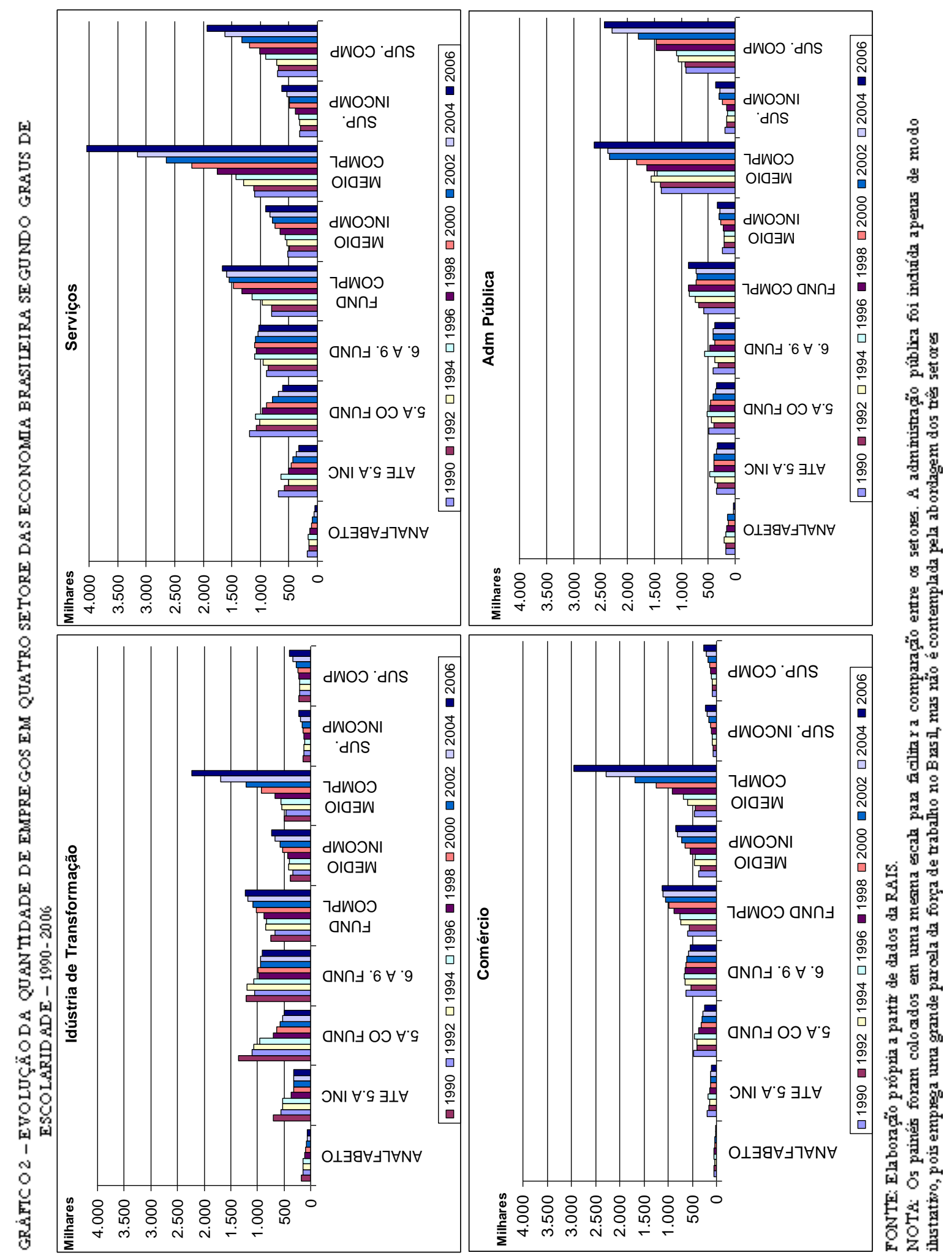


Em resumo, o Gráfico 2 mostra que a indústria de transformação está, cada vez mais, empregando uma mão-de-obra com qualificação média, liberando, proporcionalmente, a força de trabalho com os níveis mais baixos e mais altos de qualificação. Já o setor de serviços (em conjunto com o comércio) tem absorvido uma grande parcela de pessoas com ensino fundamental, médio e superior completos, o que mostra que existe mais de um padrão de absorção.

Ainda, destaca-se a geração de postos de trabalho para pessoas com o ensino médio completo em todos os setores. Dos empregos líquidos criados no período, $72 \%$ se destinaram às pessoas com este grau de escolaridade.

\section{CONCLUSÃO}

O setor de serviços (incluindo o comércio) tem absorvido parcelas crescentes da força de trabalho no Brasil, ao passo que a indústria de transformação apresentou queda ou estabilidade na proporção de empregos gerados entre 1990 e 2005, com uma pequena elevação a partir de 2006. Essas tendências condizem com a abordagem dos três setores descrita na seção dois, uma vez que a produtividade da indústria brasileira aumentou no período.

Contudo, a mão-de-obra dispensada na indústria de transformação brasileira é pouco ou altamente qualificada (esta última apresenta dispensa em termos proporcionais, mas não em termos absolutos). O setor se caracteriza pela geração de postos de trabalho com nível de qualificação intermediário. Depreende-se que isto seja reflexo da atividade industrial no país, mais caracterizada por reproduzir a tecnologia estrangeira do que desenvolvê-la domesticamente, além de se concentrar na produção de bens que não estão na fronteira tecnológica ou próxima desta.

No que se refere ao setor serviços, existem pelo menos três padrões que se destacam: absorção crescente de pessoas com baixa qualificação (fundamental completo), absorção crescente de pessoas com qualificação intermediária (ensino médio completo) e absorção crescente de pessoas com qualificação alta (superior completo).

Portanto, pode-se inferir que o setor de serviços auxiliou no aumento da produtividade no país, sobretudo via interação com o setor industrial, ao absorver grande parcela de mão-de-obra qualificada. Por outro lado, respondeu pelo aumento de atividades com baixos requisitos de escolaridade e, portanto, com baixos níveis de agregação tecnológica. Adicionalmente, cabe ressaltar que parte da elevação da qualificação dos setores foi devido a um aumento da oferta de trabalhadores qualificados com a política de 
universalização da educação fundamental e do ensino médio, além dos incentivos ao crescimento do ensino superior privado a partir dos anos 90 .

\section{REFERÊNCIAS}

BAUMOL, W. J. (1967). Macroeconomics of Unbalanced Growth: The Anatomy os Urban Crisis. The American Economic Review, Vol. 57, Issue 3.

Cadastro Geral de Empregados e Desempregados (CAGED). Brasília: MTE. Disponível em: www.mte.gov.br. Acesso em: 10/09/2008.

FISHER, A. G. B. (1952). A Note on Tertiary Production. The Economic Journal, Vol. 62, No. 248.

FURTADO, C. (1972). Análise do Modelo Brasileiro. Rio de Janeiro: Editora Civilização Brasileira, 2 a edição.

HIRSCHMAN, A. O. (1958). The strategy of economic development. New Haven:Yale University Press.

KALDOR, N. (1957). A Model of Economic Growth. The Economic Journal, 67 (268): 591-624.

KRÜGER, J. J. (2008). Productivity and structural change: a review of the literature. Journal of Economic Surveys. Vol. 22, No. 2, pp. 330-363

NELSON CARVALHEIRO, N. (2003). Uma decomposição do aumento da produtividade do trabalho no Brasil durante os anos 90. Revista de Economia Contemporânea. Rio de Janeiro, 7(1): 81-109, jan./jun. 2003.

PORCILE, G. et al (2008). Structural Change and the Service Sector in Brazil. Disponível em: http://ideas.repec.org/p/fup/wpaper/0002.html. Acesso em: 20/11/2008.

Relação Anual de informações Sociais (RAIS). Brasília: MTE. Disponível em: www.mte.gov.br. Acesso em: 10/09/2008.

ROWTHORN, R.; RAMASWAMY, R. (1999). Growth, Trade and Deindustrialization. IMF staff Papers. Vol.46, No 1.

SCATOLIN, F. D. et al (2007). Desindustrialização? Uma análise comparativa entre Brasil e Paraná. Disponível em: http://www.economia.ufpr.br/publica/textos/textos.htm. Acesso em: 10/10/2008.

SCHETTKAT, R.; YOCARINI, L. (2003). The Shift to Services: A Review of the Literature. IZA Discussion Paper No. 964. 